\title{
SÍMBOLOS Y SIMBOLISMOS CIERTOS Y FALSOS EN LA OBRA DE ANTONIO GAUDÍ
}

\author{
Juan BASSEGODA NONELL \\ Hon. FAIA
}

Con razón comentaba el Prof. George R. Collins (1917-1993) que a Gaudí los críticos e historiadores lo habían tildado de modernista, hiperrealista, organicista, barroco y de otras lindezas, cuando en realidad Gaudí no perteneció a ningún estilo ni movimiento artístico, aunque de todos ellos tenía trazas.

El simbolismo propuso confrontar la realidad con el símbolo, la apariencia con la substancia. Paul Gauguin llegó a decir que el simbolismo es la expresión de la idea a través de la forma.

Esencialmente el simbolismo es patrimonio de los escritores, desde Mallarmé a Rimbaud, con proyecciones en la pintura con el ya citado Gauguin o con Odilon Redon. En arquitectura es más complejo intentar la calificación de simbolistas para algunos edificios. Por todo ello se trasladó la idea del simbolismo literario al Modernismo arquitectónico, sin que quede muy clara tal relación.

A Gaudí se le sitúa erróneamente en el Modernismo por simple comodidad cronológica, sin que su arquitectura, derivada directamente de la geometría de la Naturaleza, se despegue totalmente del encantador pero fatuo estilo modernista. Al Modernismo se le sitúa dentro de la belle époque mientras que a Gaudí, por su independencia de toda escuela o estilo, debería colocársele en una hors époque.

El Dr. Hou-Teh Chien, en su tesis doctoral sobre Gaudí, dice que Gaudí fue un filósofo que expuso sus ideas mediante la construcción de edificios. Los edi- 
ficios de Gaudí son metáforas de sabios principios filosóficos. Aquí hay una coincidencia con la frase de Gauguin, el simbolista expresa sus ideas a través de formas pictóricas, la forma es la expresión de la idea.

Otro punto interesante a considerar en el pensamiento simbolista es la relación de este movimiento artístico con el misticismo y el ocultismo, con la consideración del poeta como sacerdote que pretende substituir a Dios.

La arquitectura de Gaudí es clara y diáfana como agua de nieve, halla sus formas en la Naturaleza que siempre actúa con lógica y sin intentos de creación artística, solamente con propósito funcional y práctico.

Los símbolos de los edificios de Gaudí son transparentes e inequívocos y, a fuerza de ser lógicos y evidentes, confunden a muchos observadores deseosos de encontrar en el gato un número de patas distinto a los dos pares.

Basta pasar revista a lo que quiso decir Gaudí con sus formas tridimensionales. Con el fin de facilitar el examen se pueden agrupar estos símbolos en cuatro grandes grupos, a saber: 1 . Símbolos cristianos; 2. Símbolos mitológicos; 3. Símbolos patrióticos; y 4. Falsos símbolos fruto de imaginaciones ajenas a la de Gaudí.

1. Símbolos religiosos: De la Biblia y de la tradición cristiana se sirvió Gaudí para poner ciertas expresiones en sus edificios. La Sagrada Familia se ha llamado la Biblia en piedra pues en ella, de modo ingenioso y completo se presentan todas las verdades de la Religión.

Del Apocalipsis sacó Gaudí modelo para la Puerta de Cementerio, ejercicio de la Escuela de Arquitectura en 1875, para el retablo de la capilla del Santísimo de San Félix de Alella (1883), para la Virgen de bronce que debía coronar la casa Milà (1910).

La representación del Calvario de la tumba de Jesús, debía representarse en la capilla del Park Güell (1900) o en la iglesia nueva de la Colonia Güell (19081915), las nueve jerarquías angélicas en la capilla de la Virgen Asunta de Rancagua (Chile) en 1922, el Monte Carmelo y los corazones traspasado de la Virgen y transverberado de Santa Teresa en el Colegio Teresiano (1889), la Resurrección de Cristo en el camino de la Santa Cueva de Montserrat (1903), el altar de piedras vírgenes de las columnas de la cripta de la Colonia Güell según el Éxodo (1909), la cruz de cuatro brazos y los monogramas de Jesús, María y José en la casa Calvet (1898), Teresianas (1889), Batlló (1906) y Milà (1910). Los 
atributos episcopales en las torres de la Sagrada Familia (1925) o en el palacio episcopal de Astorga (1889-1893).

2. Símbolos mitológicos. En dos significadas ocasiones Gaudí se sirvió de referencias a la mitología clásica griega. Se trata de la conversión del parque de la Finca Güell en el jardín de las Hespérides en homenaje al I Marqués de Comillas. La idea partió de mosén Jacinto Verdaguer y de don Eusebio Güell, Gaudí la desarrolló magníficamente especialmente por lo que se refiere a la reja del dragón encadenado donde demostró su conocimiento del arte de la forja. El segundo caso es el intento de convertir la ciudad jardín del Park Güell en una nueva Delfos para relacionar la Renaixença con la cultura helénica clásica. En este caso la idea fue de Eusebio Güell y Gaudí se vio obligado, a regañadientes, a construir un templo en estilo dórico griego, cosa que nunca volvió a hacer en ninguno de los estilos greco-romanos.

3. Símbolos patrióticos. En la romántica época de la Renaixença nada tiene de particular que Gaudí estuviera de acuerdo en que en sus obras aparecieran signos de patriotismo. En el proyecto de farolas para la Muralla de Mar (1880) hay una completa serie de alusiones a los almogávares en Oriente y a los almirantes catalanes, en la casa Calvet (1898) y en la Pedrera (1910) se representan los emblemas de los Juegos Florales, Fe, Pàtria, Amor. En la fachada de la casa Botines de León (1892) figura la imagen de San Jorge, patrón de Cataluña, en Bellesguard (1909) y en el palacio Güell (1888) el escudo de Aragón en vidrio de colores y hierro forjado. En un cielo raso de la Pedrera hay una leyenda : $O h$ Maria, no et sàpiga greu lo ser petiteta perquè també ho son les flors i les estrelles, interpretación de unos versos de Francesc Matheu Fornells (1851-1938), gran impulsor de los Juegos Florales, escritor y editor de fama. La interpretación gaudiniana consistió en añadir el nombre de la Virgen María, inexistente en el poema de Matheu.

4. Los supuestos símbolos de Gaudí. El gusto por lo misterioso y el placer de encontrar la solución a los misterios ha sido deporte practicado por historiadores y críticos de todas las épocas. Comprobar los evidentes símbolos religiosos, mitológicos o patrióticos de Gaudí es tarea poco agradecida por el público, en cambio buscar torcidas interpretaciones, plantear deducciones carentes de lógica o inventar patrañas es algo que tiene mucha salida entre el personal. Y Gaudí ha sido víctima de numerosos mitómanos que lo han catalogado como masón, templario, alquimista, drogadicto, suicida, negrero y muchas lindezas más. A veces con buena intención, como suponer que la cubierta de la casa Batlló es una interpretación de San Jorge. La torre sería la empuñadura de la espada y el remate cerámico del desván el lomo del dragón herido. Basta analizar la propuesta para 
comprender su error. La espada termina en una cruz de cuatro brazos que la haría inmanejable. Más podría pensarse en la llave de un grifo que en la empuñadura de un arma blanca. El dragón no tiene cabeza ni cola, es como un tronco de merluza a la vasca y no se entiende cómo se puede representar a San Jorge sin la figura del santo. El dragón no basta para figurar al caballero de Capadocia como un perro no es símbolo de San Roque o un cerdito el de San Antón, abad.

Un sombrerete de cerámica troceada de color rojo con adición de medias tacitas de chocolate hizo ver en un biógrafo de Gaudí una representación de la Amanita muscaria, una seta alucinógena, de lo que se dedujo que Gaudí era drogadicto. Mucho debió serlo cuando coronó la portería del Park Güell con una seta de tal tipo. En el otro pabellón hay un sombrerete semejante de forma pero recubierto con troceado de azulejo de colores distintos. Como el biógrafo no encontró ninguna seta que se le pareciera, omitió todo comentario. Menos mal que la Amanita era la muscaria, pues si llega ser faloides quién sabe qué torpes interpretaciones se hubiesen deducido. Otro fragmento de troceado cerámico contiene la expresión «Alaba por» y de aquí cambiando el orden de las letras se obtiene «Labor» que sería el nombre de la Casa Masónica. No cayó el interpretador que no hacía falta cambiar las letras de sitio, simplemente cambiando el orden de las palabras se consigue «Por Alaba», un homenaje a la capital de Euskadi. Sin embargo observando los trozos de cerámica se comprueba que están dentro de una cenefa que contenía la frase «Alabado sea por siempre el Santísimo Sacramento», de muy poco contenido masónico.

Los balcones de hierro colado de la casa Batlló se ha dicho que son máscaras para la rúa del Carnaval que desfilaba por el paseo de Gracia, que ya es decir, pero otro interpretador ve en estos balcones calaveras y los masones suelen usar este símbolo en ocasiones. Según esta teoría todos los ingenieros que levantan torres metálicas para líneas de alta tensión son masones, pues colocan un letrero con una calavera y dos tibias cruzadas con la leyenda «No tocar, peligro de muerte» o en italiano «Chi toca i fili, muore».

Un agudo investigador afirmaba que Gaudí era Templario ya que a la Sagrada Familia se le dice en catalán «el Temple».

El alquimismo de Gaudí se deduce de ciertas frases suyas que sólo pueden ser pronunciadas por los iniciados en la Cábala. Quien tal afirmación hizo, añadió: «Y Vd. también ha escrito frases que demuestran que es un iniciado en la Cábala». Me quedé de una pieza y le rogué que me proporcionara un almirez y una pizca de azufre para empezar a buscar la piedra filosofal. 
Se hace correr que Gaudí se suicidó arrojándose bajo las ruedas de un tranvía, precisamente cuando se dirigía a la iglesia de San Felipe Neri para la Estación ante el Santísimo. Además disponiendo del campanario de San Bernabé recién terminado en la Sagrada Familia, ¿qué mejor lugar para un suicidio de altura?

Feliu Elias insinuó que Gaudí trató a su ayudante Francisco Berenguer Mestres (1866-1914) como un negrero y que la temprana muerte del ayudante a los 48 años se debió a los inhumanos esfuerzos a que le sometió el arquitecto. Basta leer las declaraciones del propio Berenguer y de los demás colaboradores para comprender la devoción que sintieron por el maestro.

Alguien se dio cuenta de que la losa sepulcral de Gaudí en la capilla del Carmen de la cripta de la Sagrada Familia tiene grabadas en las esquinas cuatro cruces de Malta lo que lleva de nuevo a los Templarios. Lo malo es que esta lápida se instaló en 1939 substituyendo a la que fue destruida en 1937 y en la que sólo figuraba «Antoni Gaudí Cornet, al Cel sia».

Detrás de la actual escuela del Park Güell, antigua residencia de don Eusebio, hay un porticado con una tosca figura de piedra que tenía un brazo maltrecho y le faltaba la mano. La figura lleva un extraño sombrero en forma de tronco de cono invertido que se sujeta con la mano del brazo aún entero. Un historiador dedujo que aquella era una representación minoica como la que procedente de Creta figura en el museo del Louvre y en la mano que falta debió llevar la figura de una victoria alada. Una fotografía anterior a la pérdida de la mano muestra que la escultura representaba una lavandera que sostenía el cesto de la ropa sobre la cabeza y en la otra mano llevaba una pala de madera para sacudir la ropa en el lavadero. Ni Creta, ni la cultura minoica ni las victorias, sean aladas o ápteras, una sencilla lavandera.

En la azotea de la casa Milà hay una inscripción grabada en los azulejos de una salida de escalera. Se puede leer: «M. 1910. Rebled». Se afirmó que tal inscripción era un mensaje subliminal dejado allí por Gaudí para enseñanza de futuras generaciones. M. sería la inicial de María y «rebled» una desconocida palabra en latín de baja época que con el tiempo se lograría interpretar. Pues bien resulta que Miguel Rebled era el administrador de don Pedro Milà y uno de los albañiles de la obra en construcción en 1910 se entretuvo en grabar su nombre. Desapareció el mensaje subliminal gaudiniano.

El número de interpretaciones gratuitas de la arquitectura gaudiniana por autores como Rojo, Llarch o Carandell es casi infinita y demuestra una gran erudición y al mismo tiempo una fantasía morisca extraordinaria. Lástima que no tie- 
nen por dónde agarrarse a la realidad, ni el menor rigor en proporcionar claras demostraciones a los asertos que propugnan.

A Gaudí debe agradecerse que su fértil imaginación haya servido para desencadenar la febril fantasía de tantos especuladores de la erudición.

En una entrevista radiofónica uno de estos autores afirmaba que Gaudí era masón pero fue incapaz de decir a qué logia pertenecía, con lo que su afirmación cayó en saco roto.

El excitante mundo de Gaudí ha generado, genera y generará otras fantasías para goce y disfrute de ingenuos y para diversión de los conocedores del sentido humano, cristiano y artístico de este singular personaje de la arquitectura.

\section{BIBLIOGRAFÍA}

BASSEGODA NONELL, Juan. 1998. Iconografía apócrifa gaudiniana. Coloquios de Iconografia, Madrid, F.U.E.

Carandell, Josep Maria. 1997. El Temple de la Sagrada Família, Sant Lluís (Menorca), Triangle Postals.

- 1998. Park Güell. Utopía de Gaudi, Sant Lluís (Menorca), Triangle Postals.

Castellar-Gassol, J. 1999. Gaudí. Vida d'un visionari, Barcelona, Edicions de 1984.

ELIAS, Jordi. 1961. Gaudí, assaig biogràfic, Barcelona, Circo.

FERNÁNDEZ DE CASTRO Y BARAS, Rafael. 1981. Una primera aproximación a don Antonio Gaudí alquimista, Palma de Mallorca, diciembre de 1981 (inédito).

LlARCH, Joan. 1982. Gaudí. Biografia màgica, Barcelona, Plaza \& Janés.

MiLÁ, Ernesto. 1994. El misterio de Gaudí, Barcelona, Martínez Roca.

TellarinI, Gabrielle. 1986. A. Gaudí. Architettura e simbolo, Roma, Luisè.

Rojo Albarrán, Eduardo. 1987. Antonio Gaudí, ese desconocido, Sant Cugat del Vallés, A. Romero ed.

- 1997. El Park Güell. Historia y simbología, Sant Cugat del Vallés, A. Romero ed.

VV. AA. 1990. Gaudí i el seu temps, Barcelona, Barcanova. 